\title{
Properties of Carbonitrided Layer Formed on TiNbSn Shape Memory Alloy
}

\author{
Moataz H. Ata ${ }^{1}$, F. M. El-Hossary ${ }^{2}$ and A. M. Abd El-Rahman ${ }^{3}$
}

\begin{abstract}
The aim of this study to improve the mechanical and tribological properties of TiNbSn shape memory alloy (SMA) by rf plasma carbonitriding for using in in a bio-medical implementation. The treatment process was proceed at low working gas pressure of $0.075 \mathrm{mbar}$ in the nitrogen-acetylene gaseous mixture to produce a superficial carbonitrided layer. The rf inductively coupled were used to treat samples at different plasma processing power from 300 to $500 \mathrm{~W}$ and for a fixed time 15 minutes. The microstructure and properties such as mechanical and tribo-logical of the untreated and treated TiNbSn samples were inspected. The surface hardness is improved by rf plasma carbonitriding to a maximum of $491 \mathrm{HV}$ for plasma-processing power of $400 \mathrm{~W}$, and the friction coefficient decrease to 0.463 for the sample treated at $400 \mathrm{~W}$.
\end{abstract}

Keywords - Plasma Carbonitriding, TiNbSn, Wear, Hardness, SMA.

\section{INTRODUCTION}

Nowadays, titanium and its alloys are utilized for industrial, aerospace, and medical applications. Among them, near equiatomic NiTi alloy is one of the most interesting materials owing to their unparalleled shape memory and superelasticity demeanor, and good biocompatibility [1-3]. However, the Ni hypersensitivity and toxicity of $\mathrm{Ni}$ have been indicated in $\mathrm{Ti}$ $\mathrm{Ni}$ alloys [4]. For this reason, it was necessary to develop the $\mathrm{Ni}$-Ti shape memory alloys with small amount of $\mathrm{Ni}$ or $\mathrm{Ni}$ free Ti-based SMAs is robustly demand [5]. $\mathrm{Ti}-\mathrm{Nb}$ based alloys are favourable candidates to substitute Nitinol, especially in biomedical applications [6]. Science the discovery of shape memory effect in Ti-Nb alloys in 1970s [7], a large scale of research is being proceed on these alloys for biomedical applications [8-11]. Ti-Nb based alloys are used for biomedical applications because of its outstanding biocompatibility, low elastic modulus [12, 13], and good shape memory effect [14]. In medical applications, the microstructure and surface properties of $\mathrm{Ti}-\mathrm{Nb}$ play an important role $[15,16]$.

Different types of plasma surface treatment techniques are investigated to improve the mechanical performance and to

Moataz Bellah Hassan $\operatorname{Ata}^{1}$ is with the Department of Mechanical Engineering, Faculty of Industrial Education, Sohag University, Sohag, Egypt (corresponding author's moatzata@yahoo.com)

Fayez Mahmoud El-Hossary ${ }^{2}$ is with the Department of Physics, Faculty of Science, Sohag University, Sohag, Egypt.

Ahmed Mohamed Abd El-Rahman ${ }^{3}$ is with the Department of Physics, Faculty of Science, Sohag University, Sohag, Egypt. increase the service life of these alloys in different applications [9]. Among these types, rf plasma carbonitriding with nitrogen/acetylene gaseous mixture has been used before for surface modification of AISI 321 grade [17-19]. It has been able to realize an anticorrosive and wear-resistant superficial top layer with low friction coefficient $[17,20]$.

The principle advantages of plasma carbonitriding method are decreased process period; the ability to treat complex shape parts; and the disposal of unfavorable effects upon the surface smoothness of the treated parts. Moreover, the layers fabricated by this method are more resistant to wear and fatigue and show better plasticity properties [21, 22].

This work is conducted to fabricate a carbonitrided layer into the top of $\mathrm{Ti}-\mathrm{Nb}-\mathrm{Sn}$ substrate using RF plasma treatment, So as to get better tribo-logical and mechanical realization to reduce the price of orthopedic implants. The properties and the characteristics of the TiNbSn treated samples are estimated using X-ray diffraction (XRD), optical microscopy, microhardness tester, surface profile, oscillating ball-on-disk tribometer

\section{II.EXPERIMENTAL WORK}

\section{A. Sample Treatment}

Ti-Nb-Sn shape memory alloy substrates with dimensions of $10 \mathrm{~mm} \times 5 \mathrm{~mm} \times 3 \mathrm{~mm}$ were used in this study. The chemical composition of these SMA is $(84.35$ at.\% Ti -11.66 at.\% $\mathrm{Nb}$ and 3.99 at.\% Sn). The substrates were polished mechanically and then cleaned ultrasonically in acetone, them into the plasma reactor tube. The samples were carbo-nitrided using radio frequency $(\mathrm{RF})$ plasma inductively coupled operated in continuous mode. Details of the system was used somewhere else [23, 24].

In summarize, the RF plasma method is included in a quartz reactor tube with $500 \mathrm{~mm}$ length and $41.5 \mathrm{~mm}$ diameter and it was evacuated to $1.0 \times 10-2$ mbar base pressure by a two-stage rotary pump. The Ti-Nb-Sn samples were centered in the RF coil on a supported bar which is fixed on a water-cooled copper sample holder. The carbo-nitrided process was performed using a gas mixture containing 90\% N2 and 10\% $\mathrm{C} 2 \mathrm{H} 2$, and the gas flow rates were adjusted to establish a total gas pressure of $7.5 \times 10-2$ mbar, as measured by a capacitance manometer. The induction copper coil, energized by an RF power generator model HFS $2500 \mathrm{D}$ at $13.65 \mathrm{MHz}$ via a tunable matching network, generated the discharge. The 
samples were treated at a different plasma- processing power $300 \mathrm{~W}, 400 \mathrm{~W}$ and $500 \mathrm{~W}$ at processing time of 15 minutes. After the carbo-nitrided process, the samples were allowed to cool slowly in the evacuated reactor plasma tube.

\section{B. Sample Characterization and Testing}

Crystal structure of the Ti-Nb-Sn SMA samples after and before carbo-nitried was analyzed by X-ray diffraction using (Philips-PW1710 diffractometer) with $\mathrm{Cu} \mathrm{K} \alpha$ radiation of $\lambda=$ $1.541838 \AA$. The scans were obtained with a $0.02^{\circ}$ step size in a range from $20^{\circ}$ to $100^{\circ}$. The morphology of substrates surface after and before carbo-nitried was obtained by Olympus BX51 optical microscope. Vickers microhardness measurement was measured by a Leitz Durimet microhardness tester equipped with $25 \mathrm{mf}$ static loads. The friction coefficient was utilized at $10 \mathrm{~mm} / \mathrm{s}$ as a mean sliding speed with $1 \mathrm{~N}$ normal load. A $3 \mathrm{~mm}$ tungsten carbide (WC) ball was used as counterpart material without lubrication at room temperature in air atmosphere with humidity of 35\% - 40\%. Wear measurements were conducted depending on ASTM G133-10 standard test method. Wear track were measured by Form Talysurf 50. The $\mathrm{K}=\mathrm{V} / \mathrm{SF}$ equation were used to obtain the rate of wear, where $\mathrm{V}$ is the wear volume in $\mathrm{mm} 3, \mathrm{~S}$ is the total sliding distance in $\mathrm{m}$ and $\mathrm{F}$ is the applied load in $\mathrm{N}$.

\section{RESULTS AND DISCUSSION}

\section{A. X-Ray Analysis}

The chemical composition of the TiNbSn SMA sample before carbo-nitride treatment has been identified with EDX elemental analysis and is observed to be Ti84Nb12Sn4. Crystal structure of the Ti-Nb-Sn SMA samples after and before carbo-nitried at different plasma-processing powers; 300, 400 and $500 \mathrm{~W}$ are presented in Fig. 1.

The patterns indicate that the main phases observed after acarbo-nitrided of the samples are five spectral lines appear at different angles $\square \square \square \square$ follow; 38.92o, 41.76o, 48.84o, $72.92 \mathrm{o}$ and $88.08 \mathrm{o}$ corresponded to NbTi4 (111), (Nb0.03Ti0.97)Sn3 (202), Ti6Sn5 (214), NbTi4 (220) and Ti3Sn (204) respectively. For the treated sample at plasma power of $300 \mathrm{~W}$, the spectral line at angle of 38.920 is minimized and the rest four spectral lines found and appeared at the same angles as in the untreated blank sample. The XRD scanning of the treated sample at plasma power $300 \mathrm{~W}$ shows very small spectral lines for many phases such as; Sn3N4 (331) appeared at angle of $44.48 \mathrm{o}, \mathrm{NbN}(311)$ at $70.12 \mathrm{o}$ and $\mathrm{Nb} 2 \mathrm{~N} 3$ (311) at 70.92o. These peaks may be attributed to that the carbo-nitriding process at the plasma power of $300 \mathrm{~W}$ is initiated and not as well at these conditions.

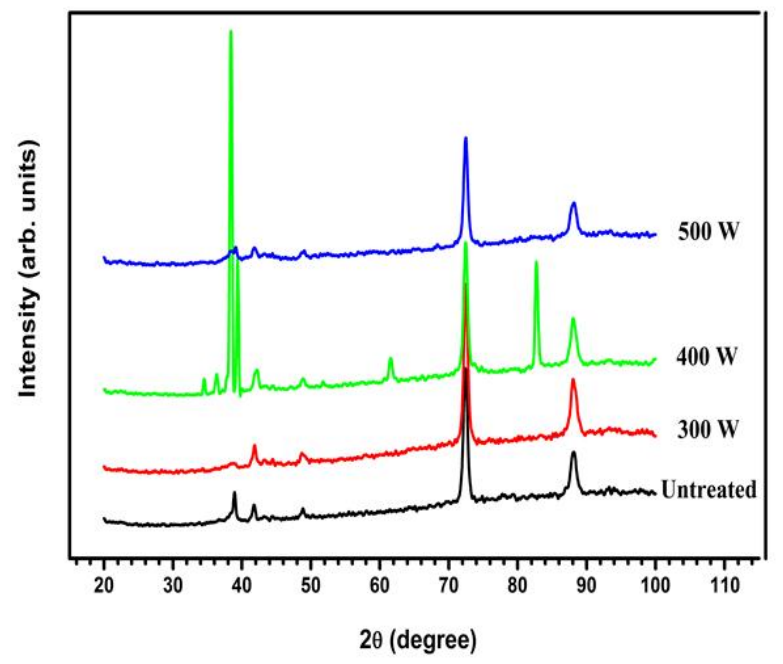

Fig. 1: The XRD patterns of the carbonitrided Ti84Nb12Sn4 at different plasma-processing power

The XRD pattern of the treated sample at plasma power of $400 \mathrm{~W}$ has spectral lines as in the untreated one except the spectral line at $38.42 \mathrm{o}$ is maximized compared with that of the untreated sample. In addition there are new phases appear at different angles such as at $34.52 \mathrm{o}$ is corresponding to $\mathrm{NbN}$ (111) phase, 36.34o corresponding to the phase of TiN (111), 40.04o to Nb4N3 (200) phase, 61.56o to Sn3N4 (531) and $82.73 \mathrm{o}$ to the phase of Nb4N3 (314). These new phases are attributed to that the nitriding process at the plasma power of $400 \mathrm{~W}$ is achieved as well at these conditions.

The XRD pattern of the treated sample at plasma power of $500 \mathrm{~W}$ much like the XRD pattern of the untreated sample. Very small peak is observed at $68.32 \mathrm{o}$ corresponding to the phase of Sn3N4 (533). This indicates that the nitriding process at the plasma power of $500 \mathrm{~W}$ is achieved but not well as in the case of $400 \mathrm{~W}$ at these conditions. The formation of $\mathrm{NbN}$ (111) and TiN (111) hard phases at a plasma power of $400 \mathrm{~W}$ are the reason for the superior mechanical and tribological properties of Ti84Nb12Sn4 carbo-nitrided [25]. According to Debye Scherrer, the mean crystallite size of the samples after carbo-nitrided treated can be determined from the X-ray diffraction patterns at different plasma power [26].

Figure 2 demonstrates the crystallite size of the untreated and treated samples compound at different plasma-processing power. One can observe from the figure that, the mean grain size increases from nearly $50 \mathrm{~nm}$ for the sample that was carbo-nitrided at plasma power of $300 \mathrm{~W}$ to approximately 90 $\mathrm{nm}$ for the sample that was carbo-nitrided at plasmaprocessing power of $500 \mathrm{~W}$. 


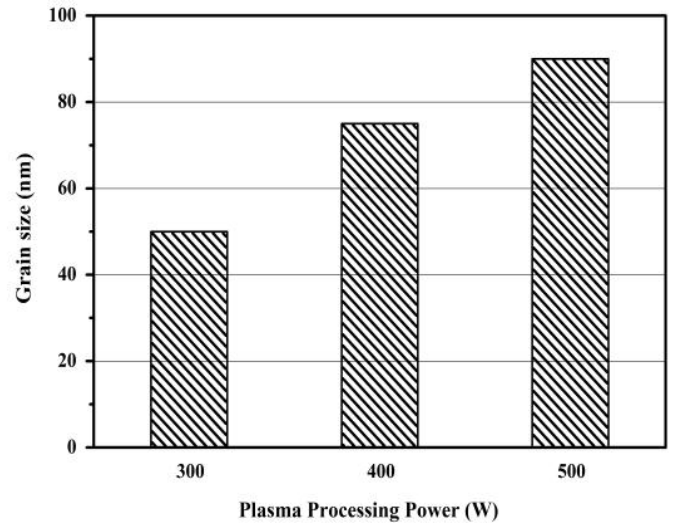

Fig. 2: Mean grain size of the carbonitrided Ti84Nb12Sn4 as a function of plasma-processing power

\section{B. Layer Thickness}

Figure 3 presents the carbo-nitrided layer thickness at different plasma-processing power. One can observe from the figure that, the layer thickness increases with increasing plasma power. The layer thickness increases from nearly $4 \mu \mathrm{m}$ for the sample that was carbo-nitrided at a processing power of $300 \mathrm{~W}$ to approximately $8 \mu \mathrm{m}$ for the sample that was carbonitrided at a processing power of $500 \mathrm{~W}$.

\section{Microhardness}

Figure 4 presents the variation of the microhardness for the untreated and carbonitrided treated samples at different plasma power. One can notice from the figure that, the microhardness increases up to $491.3 \mathrm{HV}$ as the plasma-processing power increases up to $400 \mathrm{~W}$. This value represents 2.5 -folds increase in microhardness in comparison with the untreated sample. The increase in microhardness is ascribed to the formation of $\mathrm{NbN}$, TiN hard phases, and the high intensity of NbTi4 phase. Bendavid et al. [25] have achieved a significant improvement in the surface hardness due to the presence of $\mathrm{NbN}$ and TiN hard phases. The low hardness for the sample that was treated at a plasma-processing power of $500 \mathrm{~W}$ is ascribed to the low intensity of NbTi4, $\mathrm{NbN}$ and TiN phases. The expansion of nitride and carbide phases might block the formed microcracks in the treated layer. Therefore, the rate of nitrogen and carbon penetration decreases through these microcracks. Consequently, the concentration of nitrogen and carbon in the far depth region of the compound layer decreases and then reducing of microhardness will occur to reach the lower values [27].

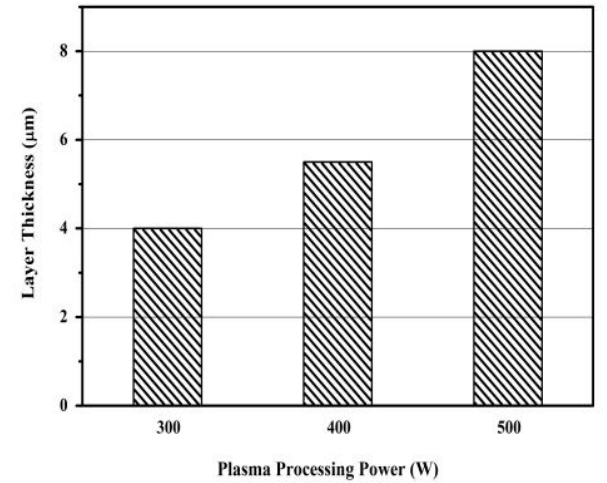

Fig. 3: Carbonitriding layer thickness at different plasma-processing power.

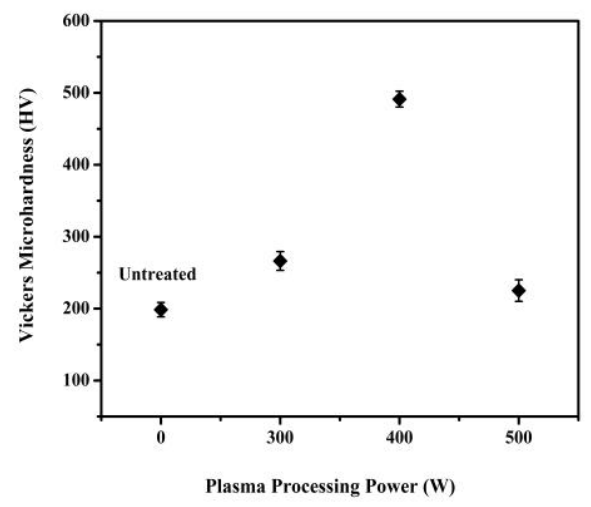

Fig. 4: Surface microhardness of the the carbonitrided Ti84Nb12Sn4 versus plasma processing power

\section{Wear and Friction Measurements}

Figure 5 shows the friction coefficient of the untreated and carbonitrided TiNbSn samples at different plasma power. From this figure one can monitor that, the friction coefficient for the carbonitrided samples decreases from nearly 0.557 for the untreated sample to nearly 0.463 for samples treated at 400 $\mathrm{W}$, representing a reduction of $17 \%$.



Fig. 5: Friction coefficient variation with plasma-processing power of untreated and carbonitrided SMA samples

The subsistence of a large volume fraction of nitrogen and carbon modulates the composition of the surface that accompanied by a lowering in coefficient of friction and rising in wear resistance.

Figure 6 and Figure 7 shows the optical micrographs and the wear track width of the untreated and carbonitrided samples at 
different plasma-processing power. Generally, it has been noticed that the track width of carbonitrided samples is narrower than that of the untreated sample, demonstrating the augmentation in wear resistance for the carbonitrided samples. The high hardness of treated sample at $400 \mathrm{~W}$ due to the high intensity of $\mathrm{NbTi}_{4}$ phase leads to decrease the wear track width and increase the wear resistance as shown in Fig. 6 and Fig. 7.



Fig. 6: Optical micrograph of wear tracks for the untreated and carbonitrided SMA samples at different plasma processing-power



Fig. 7: Wear track width for the untreated and carbonitrided SMA samples at different plasma processing-power

Figure 8 displays the wear rate of the investigated TiNbSn samples at different plasma-processing power, where the wear rate is calculated as the wear area $\times$ track length/total sliding distance. One can expose from the figure that, the rate of wear decreases as the plasma power increases. The decrease in the wear rate is ascribed to the surface strengthening resulting from the formation of hard phases of $\mathrm{NbTi} 4, \mathrm{NbN}$ and $\mathrm{TiN}$ precipitates in the near-surface region of TiNbSn.

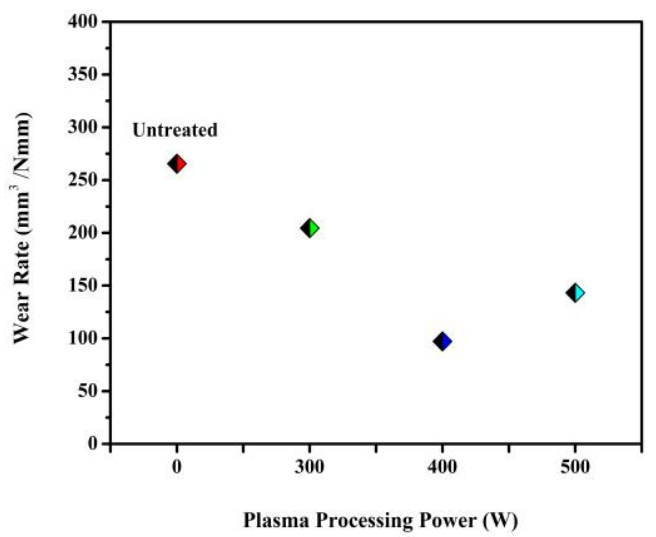

Fig. 8: The wear rate of the investigated carbonitrided SMA samples as a function of plasma-processing power

\section{CONCLUSION}

Carbonitriding by RF plasma achieved a modified surface layer into TiNbSn SMA substrate with a layer thickness varied from $4 \mu \mathrm{m}$ up to $8 \mu \mathrm{m}$. It has been found that the nitrogen/carbon solid solutions improve the surface hardness of the treated layer by more than 2.5 times compared to the untreated one. Moreover, the values of wear resistance for TiNbSn carbonitrided are improved compared to those for TiNbSn. The friction coefficient decreases from nearly 0.557 for the untreated sample to nearly 0.463 for Carbonitrided TiNbSn SMA sample.

\section{REFERENCES}

[1] D .C. Lagoudas, "Shape memory alloys: modeling and engineering applications," Springer: New York, USA, 2008.

[2] M. Ghadimi, A. Shokuhfar, A. Zolriasatein, and HR. Rostami, "Morphological and structural evaluation of nanocrystalline $\mathrm{NiTiCu}$ shape memory alloy prepared via mechanical alloying and annealing," Mater. Lett., vol. 90, pp. 30-33, 2013.

[3] M. Farooq, F. Khalid, H. Zaigham, and I. Abidi, "Superelastic behaviour of $\mathrm{Ti}-\mathrm{Nb}-\mathrm{Al}$ ternary shape memory alloys for biomedical applications," Mater. Lett., vol. 121, pp. 58-61, 2011.

[4] H. Y. Kim, Y. Ohmatsu, J. Kim, H. Hosoda and S. Miyazaki, "Mechanical properties and shape memory behavior of Ti-Mo-Ga alloys," Mater. Trans., Vol. 45, pp. 1090-1095, 2004.

[5] H. Y. Kim, H. Satoru, J. Kim, H. Hosoda and S. Miyazaki, "Mechanical properties and shape memory behavior of Ti-Nb alloys," Mater. Trans., Vol. 45, pp. 2443-2448, 2004.

[6] R.E. Mcmahon, S.V. Verkhoturov, D. Munoz-Pinto, I. Karaman, and F. Rubitschek, "A comparative study of the cytotoxicity and corrosion resistance of nickel-titanium and titanium-niobium shape memory alloys," Acta Biomater, vol. 8, pp. 2863-2870, 2012.

[7] HY. Kim, Y. Ikehara, J. Kim, H. Hosoda, and S. Miyazaki, "Martensitic transformation, shape memory effect and superelasticity of Ti-Nb binary alloys," Acta Mater., vol. 54, pp. 2419-2429, 2006.

[8] B. Wang, Y. Zheng, and L. Zhao, "Effects of Sn content on the microstructure, phase constitution and shape memory effect of Ti-Nb-Sn alloys," Mater. Sci. Eng, A, vol. 486, pp 146-151, 2008.

[9] T. Inamura, H. Hosoda, H. Kanetaka, HY. Kim, and S. Miyazaki," Phase constitution and mechanical properties of Ti-(Cr,Mn)-Sn biomedical alloys," Mater. Sci. Forum, vol. 654, pp. 2118-2121, 2010.

[10] Y. Cui., Y. Li, K. Luo, and H. Xu, "Microstructure and shape memory effect of Ti-20Zr-10Nb alloy," Mater. Sci. Eng., A, vol. 527, pp. 652$656,2010$. 
[11] T. Inamura, Y. Kinoshita, J. Kim, H. Kim, H. Hosoda, and K. Wakashima, "Effect of $\left(\begin{array}{lll}0 & 0 & 1\end{array}\right)\left(\begin{array}{lll}1 & 1 & 0\end{array}\right)$ texture on superelastic strain of Ti-Nb-Al biomedical shape memory alloys," Mater. Sci. Eng., A, vol. 438, pp. 440-865, 2006.

[12] T. Inamura, H. Hosoda, K. Wakashima, and S. Miyazaki, "Anisotropy and temperature dependence of young's modulus in textured TiNbAl biomedical shape memory alloy," Mater. Trans. Vol. 46, pp. 15971603, 2005.

[13] N. Masahashi, Y. Mizukoshi, S. Semboshi, N. Ohtsu, T.K. Jung, and S. Hanada, "Photo-induced characteristics of a Ti-Nb-Sn biometallic alloy with low Young's modulus," Thin Solid Films, vol. 519, pp. 276-283, 2010.

[14] S. Miyazaki, H.Y. Kim, and H. Hosoda, "Development and characterization of Ni-free Ti-base shape memory and superelastic alloys," Mater. Sci. Eng. A, vol. 438-440, pp. 18-24, 2006.

[15] A. Sowi nska, M. Tarnowski, W. Jakubowski, J. Oleksiak, T. Wierzcho'n, and E.Czarnowska, "Effect of nitride surface layers with different nanotopography on platelets adhesion," Eng. Biomater., vol. 119, pp. 27-32, 2013.

[16] V. Karagkiozaki, S. Logothetidis, N. Kalfagiannis, S. Lousinian, and G. Giannoglou, "Atomic force microscopy probing platelet activation behavior on titanium nitride nanocoatings for biomedical applications," Nanomed. Nanotechnol. Biol.Med., vol. 5, pp. 64-72, 2009.

[17] A. M. Abd El-Rahman, "An investigation on the microstructure, tribological and corrosion performance of AI-SI 321 stainless steel carbonitrided by RF plasma process," Surf. and Coat. Technol., Vol. 205(2), pp. 674-681, 2010.

[18] J. Piekoszewski, L. Waliśa and J. Langnerb, "Surface morphology of nitrogen-alloyed steels using high intensity pulsed plasma beams," Mater. Lett., Vol. 32(1), pp. 49-53, 1997.

[19] Y. M. Lin, J. Lu, L. P. Wang, T. Xu and Q. J. Xue, "Surface nanocrystallization by surface mechanical attrition treatment and its effect on structure and properties of plasma nitrided AISI 321 stainless steel," Acta Materialia, Vol. 54(20), pp. 5599-5605, 2006.

[20] J. Feugeas, B. Gomez and A. Craievich, "Ion nitriding of stainless steels. real time surface characterization by synchrotron X-Ray diffraction," Surf. and Coat. Technol., Vol. 154(2-3),, pp. 167-175, 2002.

[21] T. Wierzchon, and J. Michalski, " Formation and properties of composite layers on stainless steel," Mater. Sci., vol. 27, pp. 771-776, 1992.

[22] T. Wierzchon, and J.R. Sobiecki, "The PACVD method for surface layer deposition using a glow discharge in $\mathrm{H} 2+\mathrm{N} 2+\mathrm{Ti}(\mathrm{OC} 3 \mathrm{H} 7) 4$," Vacuum, vol. 44, pp. 975-978, 1993.

[23] F. El-Hossary, N.Z. Negm, S.M. Khalil, and A.M. Abd Elrahman, "Formation and properties of a carbonitrided layer in 304 stainless steel using different radio frequency plasma powers," Thin Solid Film, vol. 405, pp. 179-185, 2002

[24] .F.M. El-Hossary, N.Z. Negm, A.M. Abd El-Rahman, and M. Hammad, "Duplex treatment of 304 AISI stainless steel using RF plasma nitriding and carbonitriding," Mater. Sci. and Eng. C, vol. 29, pp. 1167-1173, 2009.

[25] A. Bendavid, P. J. Martin, T. J. Kinder, and E. W. Preston, "The deposition of $\mathrm{NbN}$ and $\mathrm{NbC}$ thin films by filtered vacuum cathodic arc deposition," Surf. Coat. Technol. Vol. 163-164, pp. 347-352, 2003.

[26] S. Mändl, and B. Rauschenbach, "Anisotropic strain in nitrided austenitic stainless steel," J. of Appl. Phys., vol. 88, pp. 3323-3329, 2000.

[27] M. Raaif, F. M. El-Hossary, N. Z. Negm, S. M. Khalil and P. Schaaf, "Surface treatment of Ti-6Al-4V alloy by rf plasma nitriding," J. of Phys.: Condensed Matter, Vol. 19(39), 2007.

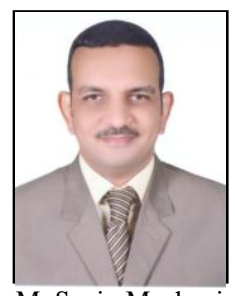

\section{$\underline{\text { Moataz Bellah Hassan Ata }}$}

Place of birth: Qena - Egypt.

Date of birth: January 7, 1976

Educational background:

B. Sc. in Mechanical Engineering (Design \& Production),

Faculty of Engineering, Assiut University, Assiut, Egypt, May 2000.

M. Sc. in Mechanical Engineering (Material Science),

Faculty of Engineering, Al-Azhar University, Nasr City, Cairo, Egypt, May 2005.

$\mathrm{Ph}$. D. in Mechanical Engineering (Material Science), Faculty of Engineering, Assiut University, Assiut, Egypt, June 2012.

Major field: Mechanical Engineering (Design and Production).

Work experience: Fabrication by $\mathrm{P} / \mathrm{M}$ technique.

Plasma synthesize of thin film coating.

Fellowship jobs: Assistant Lecture, Sohag University, Egypt, 2006-2012. Assistant Professor, Sohag University, Egypt, 2012 till now.

Current job: Head Department of Mechanical Engineering

Current research: Shape memory alloys coatings and bulk fabrication.

Previous research: Crack initiation prediction. 